\title{
Localization of PDZD7 to the Stereocilia Ankle-Link Associates this Scaffolding Protein with the Usher Syndrome Protein Network
}

\author{
M'hamed Grati, ${ }^{1}$ Jung-Bum Shin, ${ }^{2}$ Michael D. Weston, ${ }^{3}$ James Green, ${ }^{4}$ Manzoor A. Bhat, ${ }^{4}$ Peter G. Gillespie, ${ }^{2}$ \\ and Bechara Kachar ${ }^{1}$ \\ ${ }^{1}$ Laboratory of Cell Structure and Dynamics, National Institute on Deafness and Other Communication Disorders, National Institutes of Health, Bethesda, \\ Maryland 20892, ${ }^{2}$ Oregon Hearing Research Center, Oregon Health and Science University, Portland, Oregon 97239, ${ }^{3}$ Department of Oral Biology, Creighton \\ University School of Dentistry, Omaha, Nebraska 68178, and ${ }^{4}$ Laboratory of Cell and Molecular Physiology, University of North Carolina, Chapel Hill, North \\ Carolina 27599
}

Usher syndrome is the leading cause of genetic deaf- blindness. Monoallelic mutations in PDZD7 increase the severity of Usher type II syndrome caused by mutations in USH2A and GPR98, which respectively encode usherin and GPR98. PDZ domain-containing 7 protein (PDZD7) is a paralog of the scaffolding proteins harmonin and whirlin, which are implicated in Usher type 1 and type 2 syndromes. While usherin and GPR98 have been reported to form hair cell stereocilia ankle-links, harmonin localizes to the stereocilia upper tip-link density and whirlin localizes to both tip and ankle-link regions. Here, we used mass spectrometry to show that PDZD7 is expressed in chick stereocilia at a comparable molecular abundance to GPR98. We also show by immunofluorescence and by overexpression of tagged proteins in rat and mouse hair cells that PDZD7 localizes to the ankle-link region, overlapping with usherin, whirlin, and GPR98. Finally, we show in LLC-PK1 cells that cytosolic domains of usherin and GPR98 can bind to both whirlin and PDZD7. These observations are consistent with PDZD7 being a modifier and candidate gene for USH2, and suggest that PDZD7 is a second scaffolding component of the ankle-link complex.

\section{Introduction}

Usher syndrome type 1 (USH1) and 2 (USH2) proteins are essential for hair cell stereocilia development and mechanotransduction (MET) (Schwander et al., 2010; Pan and Zhang, 2012; Yang et al., 2012). The MET complex is built around both ends of the tip-link. USH1 proteins form a very distinctive functional and structural network that is part of the MET complex. Cadherin-23 $(\mathrm{CDH} 23)$ and protocadherin-15 form the tip-link (Kazmierczak et al., 2007), while harmonin, sans, and myosin VIIa (MYO7A) are clustered at the upper tip-link insertion density (UTLD) (Grati and Kachar, 2011). Harmonin is presumed to control the UTLD slippage during MET adaptation via its dual ability to simultaneously bind stereocilia actin and CDH23 (Grillet et al.,

Received June 28, 2012; revised July 26, 2012; accepted Aug. 2, 2012.

Author contributions:M.G.,P.G.G., and B.K. designed research;M.G. and J.-B.S. performed research;M.D.W., J.G., and M.A.B. contributed unpublished reagents/analytic tools; M.G., J.-B.S., P.G.G., and B.K. analyzed data; M.G., P.G.G., and B.K. wrote the paper.

This work was supported by the Intramural Program of the National Institute on Deafness and Other Communication Disorders - National Institutes of Health, NIH DC002368 (P.G.G.), NIH DC011034 (P.G.G.), NIH GM063074 (M.A.B.), the State of North Carolina (M.A.B.) and from the Hearing Health Foundation (M.D.W.). We thank Drs. Ronald Petralia, Mark Berryman, Lisa Dunbar and Bryan Millis for their critical reading of the manuscript.

The authors declare no conflict of interest.

Correspondence should be addressed to either Bechara Kachar or M'hamed Grati, Laboratory of Cell Structure and Dynamics, National Institute on Deafness and Other Communication Disorders, National Institutes of Health, Bethesda, Maryland 20892. E-mail: kacharb@nidcd.nih.gov or Mgrati@aol.com.

J.-B. Shin's present address: Department of Neuroscience, University of Virginia, Charlottesville, VA 22908.

DOI:10.1523/JNEUROSCI.3071-12.2012

Copyright $\odot 2012$ the authors $\quad 0270-6474 / 12 / 3214288-06 \$ 15.00 / 0$
2009; Michalski et al., 2007), and MYO7A likely controls tip-link tension (Kros et al., 2002; Grati and Kachar, 2011).

Three USH2 proteins have been so far identified: usherin and GPR98 (also known as VLGR1) are plasma membrane proteins that form the ankle-links, and whirlin is thought to be a scaffold for protein interactions with these links (Michalski et al., 2007). Whirlin is also implicated in stereocilia-length regulation (Manor et al., 2011).

Molecular genetic diagnosis in many USH patient cohorts on known USH genes failed to reveal mutations in a number of patients, suggesting more USH genes remain to be identified (Bonnet et al., 2011). PDZD7, a three-PDZ domain protein with a central proline-rich region, has similar domain composition to harmonin and whirlin. A monoallelic mutation in PDZD7 acts as modifier of homozygous USH2A (encoding usherin) mutations (Ebermann et al., 2010), resulting in retinitis pigmentosa with accelerated onset and increased severity. Moreover, monoallelic deleterious mutations in PDZD7 and GPR98 were found to cause a digenic case of USH2 (Ebermann et al., 2010). Originally, a homozygous reciprocal chromosomal translocation was found to disrupt the $P D Z D 7$ gene implicated in a nonsyndromic congenital hearing impairment (Schneider et al., 2009).

Biochemical investigations demonstrated that the PDZ2 domain of PDZD7 binds the PDZ-domain interacting motif (aspartate-threonine-histidine-leucine)_containing intracellular tails of both GPR98 and usherin. In the retina, PDZD7 has been localized to the base of the connecting cilia of photoreceptors 
A

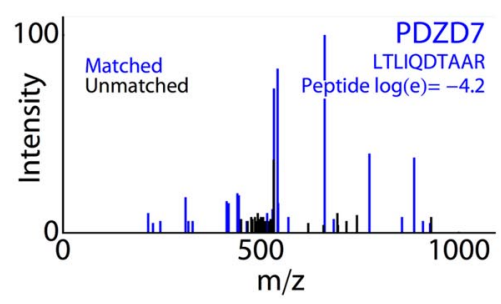

C

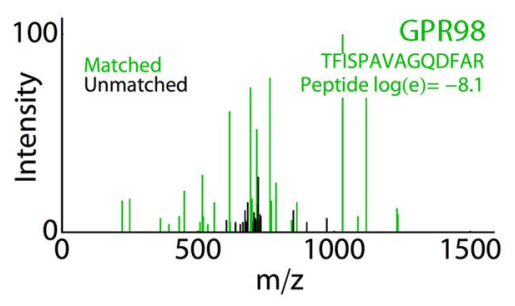

B

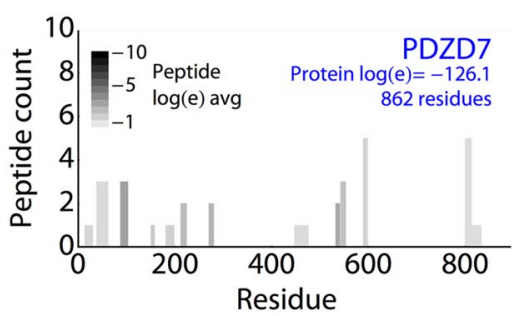

D

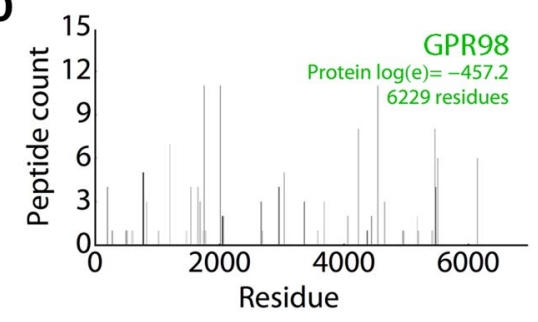

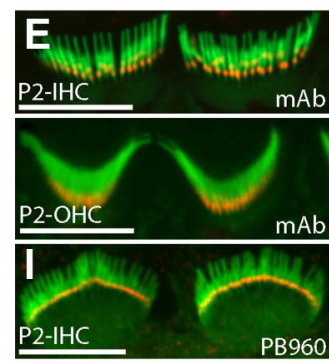
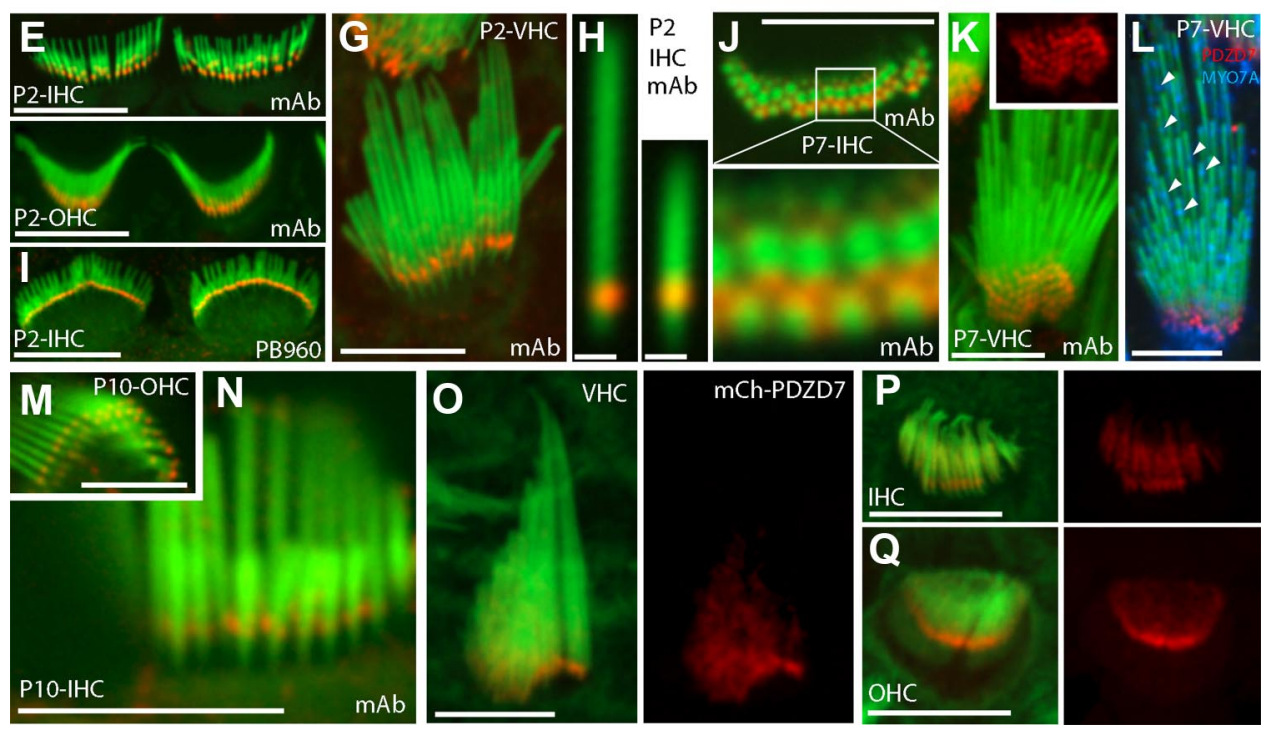

Figure 1. Detection of PDZD7 in hair cells stereocilia. A-D, Mass spectrometry analysis. $A, C$, Representative MS2 spectra for PDZD7 and GPR98 showing fragments that were either matched (colored) or unmatched (black) to hypothetical database spectra. The peptide sequence and statistical score indicating identification confidence are shown for each. $\boldsymbol{B}, \mathbf{D}$, Total peptide coverage of PDZD7 and GPR98. The width of each bar indicates the length of the identified peptide, the position of the bar along the $x$-axis corresponds to its position in the sequence, the height of the bar indicates the number of identical peptides identified, and the shading of the bar corresponds to $\log (\mathrm{e})$, the statistical significance for peptide identification, averaged over all identical peptides. The statistical score indicating identification confidence is shown for each protein. $\boldsymbol{E}-\boldsymbol{N}$, PDZD7 immunolocalization in developing rat hair cells. Confocal microscopy of inner (IHC; $\boldsymbol{E}, \boldsymbol{H}, \boldsymbol{I}, \boldsymbol{J}$, and $\boldsymbol{N})$, outer $(\mathrm{OHC} ; \boldsymbol{F}, \boldsymbol{M})$, and vestibular (VHC; $\boldsymbol{G}, \boldsymbol{K}, \boldsymbol{L})$ hair cells from postnatal (P) day $2(\boldsymbol{E}-\boldsymbol{I}), 7(\boldsymbol{J}-\boldsymbol{L})$, and $10(\boldsymbol{M}, \boldsymbol{N})$ rats immunostained with mouse polyclonal $\mathrm{YF}-\mathrm{PA2} 20973$ (mAb) and rabbit polyclonal PB960 antibodies, showing localization of PDZD7 (red) at the stereocilia ankle-link region; actin (green). $\boldsymbol{H}$, High magnification of a long and a short stereocilium from a P2 inner hair cell revealing the PDZD7 fluorescence just above the tapered base.J, Horizontal cross-section through inner HC stereocilia showing that PDZD7 immunofluorescence (red) is peripheral to the actin core (green); it is abundant between stereocilia of the same row and between stereocilia of longer and shorter rows, but excluded from the back of the tallest stereocilia. $\boldsymbol{K}$, 0blique view of P7 vestibular stereocilia showing PDZD7 fluorescence (red, inset) at the ankle-link region. $\boldsymbol{L}$, Absence of PDZD7 (red) at the upper tip-link insertion sites where MY07A (blue) is clustered (arrowheads). $\mathbf{0 - Q}$, Maturing hair cells expressing mCherry-PDZD7 showing that PDZD7 targets the ankle-link region. Scale bars: $\boldsymbol{E}-\mathbf{G}, \boldsymbol{I}-\boldsymbol{Q}, 5 \mu \mathrm{m} ; \boldsymbol{H}, 300 \mathrm{~nm}$.

(Ebermann et al., 2010). Moreover, morpholino-induced reduction of PDZD7 in zebrafish embryos led to photoreceptor death and hair cell stereocilia disorganization, mimicking the USH phenotype (Ebermann et al., 2010). These findings implicate PDZD7 in assembly/scaffolding of USH2 complex in photoreceptors and likely hair cells. In addition, since USH2 proteins play a role in development of the stereocilia hair bundle, it follows that PDZD7 might also contribute to their morphogenesis. PDZD7 was found to coimmunoprecipitate with sans and harmonin (Schneider et al., 2009); however, its subcellular localization and function in mammalian hair cells remain unknown. Here we use mass spectrometry and fluorescence microscopy to investigate subcellular localization of PDZD7 in hair cells in order to understand its potential role in the development and function of their mechanosensory stereocilia.

\section{Materials and Methods}

Mass spectrometry. Purified E20-E21 chick hair bundles were analyzed by mass spectrometry as described previously (Shin et al., 2010). Label-free protein quantitation used MS2 intensities (Spinelli et al., 2012) divided by molecular mass, normalized to the sum of all intensity/molecular mass; these normalized molar intensities $\left(i_{\mathrm{m}}\right)$ are proportional to the mole fraction of each protein (J.-B. Shin and P. G. Gillespie, unpublished observations). Peptide data analyzed here were from an X! Tandem analysis (Craig and Beavis, 2004) of 13 samples, each of 100 ears' worth of bundles (Shin et al., 2010).

Antibodies. Affinity-purified rabbit antibodies PB960/961 (Covance) were generated against peptide REAWTLDSRSPTKVRPRLDLE corresponding to mouse PDZD7 isoform-1 amino acids 486-506 (GenBank: NP_001182194.1). A mouse polyclonal anti-PDZD7 antibody (YFPA20973) directed against human PDZD7 amino acids 1-511 (AAH29054) was purchased from AbFrontier. Specificity of both 

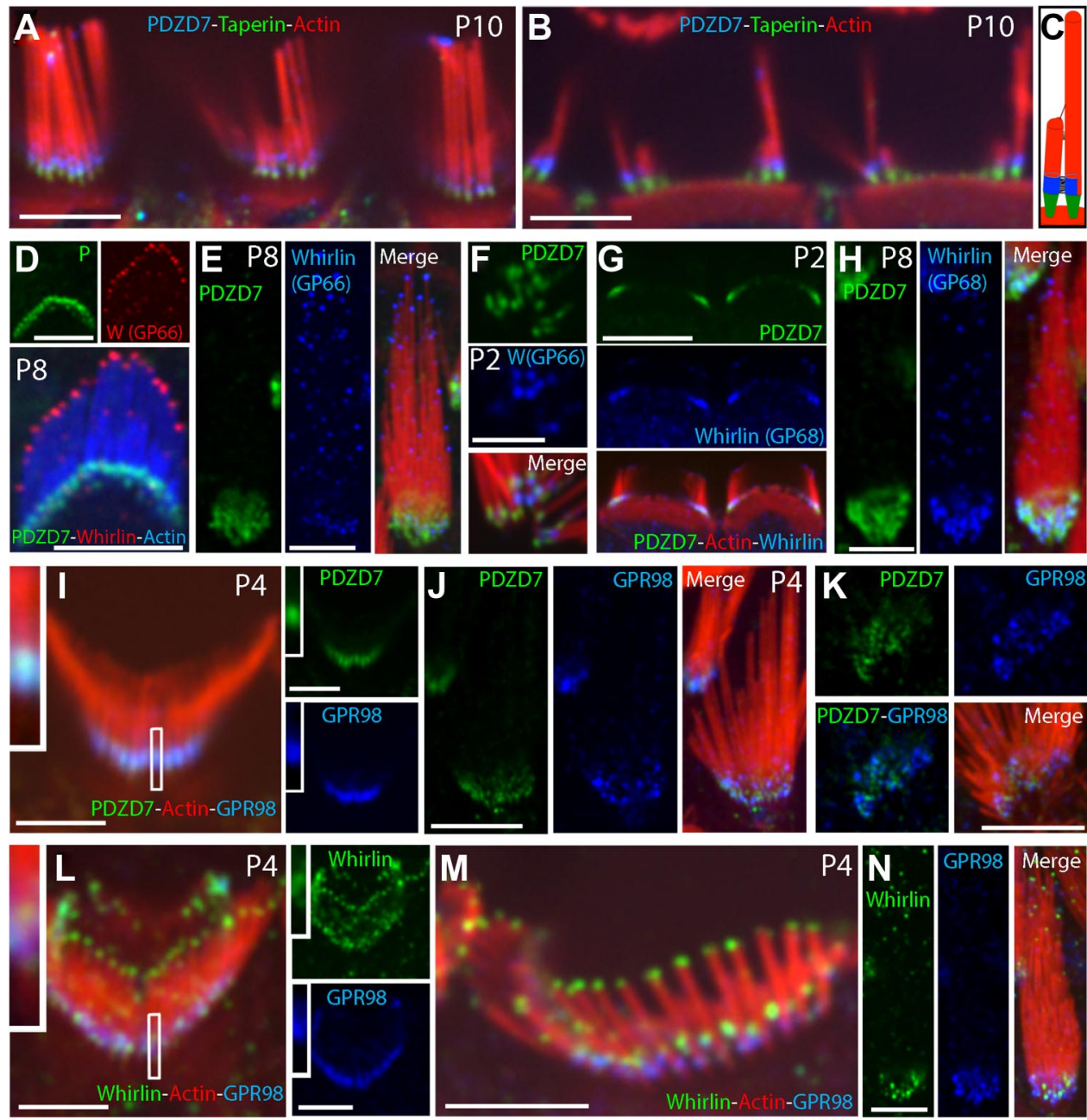

Figure 2. PDZD7 colocalization with ankle-link proteins in maturing rat hair cells. $A-C$, Colocalization of PDZD7 and taperin in hair cells. $A, B, B a c k(A)$ and orthogonal ( $B)$ views of stereocilia rows of P10 outer HCs colabeled for PDZD7 (blue) and taperin (green) showing the distribution of both PDZD7 (blue) and taperin (green) along the long and short stereocilia. Red, actin. $C$, A diagram summarizing PDZD7 (blue) and taperin (green) distribution along the stereocilia (red). D-H,PDZD7 and whirlin colocalization in developing hair cells. Whirlin is revealed with antibodies GP66 (D-F) and GP68 $(\boldsymbol{G}, \boldsymbol{H})$. D, Oblique view of P8 outer HC bundle showing immunofluorescence distribution of PDZD7 (P, green) and whirlin (W, red). Blue, actin. $\boldsymbol{E}, \boldsymbol{H}, 0$ blique view of P8 VHC stereocilia showing immunofluorescence distribution of PDZD7 (green) and whirlin (blue). Red, actin. $F$, A view of a P2 vestibular hair bundle showing partial colocalization of PDZD7 (green) and whirlin (blue); $r=0.64$ and $\mathrm{Rr}=0.60$. Red, actin. G, Orthogonal view through P2 outer HC bundles showing PDZD7 (green) and whirlin (blue) immunofluorescence at the ankle-link region. Red, actin. $\boldsymbol{I}-\boldsymbol{K}$, PDZD7 and GPR98 colocalization in P4 hair cells. I, Back view of P4 outer HC showing PDZD7 (green) and GPR98 (blue) colocalization at the ankle-link region. $J, \boldsymbol{K}, 0$ blique $(\boldsymbol{K})$ and surface $(\boldsymbol{L})$ views of P4 VHCS showing PDZD7 (green) and GPR98 (blue) colocalization at the ankle-link region $(r=0.73 ; \mathrm{Rr}=0.81 \mathrm{in} \boldsymbol{K})$. $\mathbf{L}-\boldsymbol{N}$, Whirlin and GPR98 colocalization in P4 hair cells. $\mathbf{L}$, A view of P4 outer HC showing whirlin (green) and GPR98 (blue) colocalization at the ankle-link region. $\boldsymbol{M}$, A view of P4 IHC showing whirlin (green) and GPR98 (blue) colocalization at the ankle-link region. $\boldsymbol{N}$, Front lateral view of P4 VHC showing whirlin (green) and GPR98 (blue) presence at the ankle-link region. In all three hair cell types, whirlin is also seen at the stereocilia tips $(\boldsymbol{L}-\boldsymbol{N})$. Scale bars: $\boldsymbol{A}, \boldsymbol{B}-\boldsymbol{H}, \boldsymbol{J}, \boldsymbol{K}, \boldsymbol{N}, 5 \mu \mathrm{m}$; $I, L, M, 2.5 \mu \mathrm{m}$.

PDZD7 antibodies was validated by immunocytochemistry on COS7 cells expressing mCherry-PDZD7. Guinea pig whirlin antibodies GP66 and GP68 were generated against recombinant proteins corresponding respectively to amino acids $1-234$ and 718-907 of human whirlin (GenBank: NP_056219.3) and were validated by immunocytochemistry on COS7 cells expressing GFP-Whirlin, and by absence of immunofluorescence on inner ear tissue from mutant mice from mouse strain B6.CgWhrn ${ }^{\text {wi }}$ Tyrp $1^{\mathrm{b}} /++\mathrm{J}$. Immunopurified rabbit GPR98 antibody was generated against a recombinant protein corresponding to amino acids 6152-6298 of mouse GPR98 (GenBank: AAL30812.1); the same rabbit antiserum was used in McGee et al. (2006). Rabbit immunopurified antibody against TPRN (NBP1-70732) was purchased from Novus Biologicals. PB206 anti-MYO7A antibody was described by Grati and Kachar (2011).

Inner ear tissue. All procedures followed the Oregon Health and Sciences University or National Institutes of Health (protocol 1215-11) -approved animal care protocols and guidelines. Animals from either sex were used. The Whirler mice (B6.Cg-Whrn ${ }^{\text {wi }}$ Tyrp 1 b $/++\mathrm{J}$ ) carrying a large genomic deletion in Ush2d were obtained from The Jackson Laboratory (stock no. 000571).
Immunocytochemistry. Immunofluorescence staining of PDZD7, whirlin, GPR98, taperin, and MYO7A was performed on whole-mount preparations of finely dissected organ of Corti and vestibular organs as previously described (Schneider et al., 2006). Mander's fluorescence overlap coefficient $(r)$ and Pearson's correlation coefficient (Rr) calculations (Zinchuk and Zinchuk, 2008) were performed with the NIH ImageJ software (Grati and Kachar, 2011).

Complementary DNA expression vectors. Full-length mouse PDZD7 cDNA (NM_001195265) was amplified on randomly reverse-transcribed mRNA preparation from inner ear neuroepithelia using primers $5^{\prime}$ AGTCtccggaGCACGTGGTTTCACGGTAGGCTTTGAC-3' and '5'AGTCctcgagCTAGGAAGGGTCATGGGGATCCTTAAG-3', cloned into pmCherry-C1 vector (Clontech) within BspEI and XhoI restriction sites. Constructs encoding plasma membrane interleukin-2 receptor $\alpha$-chainwhich is 200 amino-acids-long, has a single transmembrane domain, and a cytosolic $\mathrm{COOH}$ terminus (GenBank CAH73597)—the $\mathrm{COOH}$ terminus of which was fused to the cytosolic $75 \mathrm{COOH}$-terminal amino acids of mouse usherin (GenBank NP_067383.3; called IL2 $\alpha$-ush2a) and to the cytosolic $140 \mathrm{COOH}$-terminal amino acids of mouse GPR98 (GenBank AAL30812.1; 
called IL2 $\alpha$-GPR98) - were generated in a pCDNA3 expression vector (Invitrogen) using standard RT-PCR and cloning methods. All the final constructs were fully sequenced. EGFP-tagged full-length whirlin (AY739114) was a gift from Dr. Thomas Friedman (NIH, Bethesda, MD). Sans and harmonin constructs were previously described by Grati and Kachar (2011).

Culture and transfection of rat inner ear tissue. Inner ear explants were transfected using Helios gene gun as previously described (Rzadzinska et al., 2004) and incubated for $24 \mathrm{~h}$. The efficiency of transfection ranged from zero to four hair cells per tissue explant, and at least three transfected cells were examined for each condition.

Culture and transfection of LLC-PK1 and COS7 cells. LLC-PK1-CL4 cells were cultured and transfected as described by Grati et al. (2006). COS7 cells were plated on coverslips and maintained at $37^{\circ} \mathrm{C}$ in DMEM supplemented with $10 \%$ FBS. Cultures were transfected using GeneJuice (Novagen). Cells were fixed $24 \mathrm{~h}$ after transfection in 4\% PFA in PBS, permeabilized for $10 \mathrm{~min}$ in $0.5 \%$ Triton X-100, and processed for immunocytochemistry. Fluorescence colocalization evaluation was performed on at least 10 transfected cells per experiment, as described by Grati and Kachar (2011).

Scanning electron microscopy. Freshly dissected cochleae were processed for scanning electron microscopy by the OTOTO (osmiumthiocarbohydrazide-osmium-thiocarbohydrazide-osmium) method, as previously described (Manor et al., 2011) and viewed on a Hitachi S-4800 operating at $5 \mathrm{kV}$.

\section{Results}

\section{Detection of PDZD7 by mass spectrometry}

Using shotgun mass spectrometry, we identified PDZD7 in hair bundles purified from E20-E21 chicken utricles (Fig. 1A,B). We detected 33 total peptides (14 unique) for PDZD7 across 13 bundle mass-spectrometry experiments. PDZD7 was not detected in eight experiments with whole chicken utricle, indicating that it is highly enriched in hair bundles. Using MS2 intensities (Spinelli et al., 2012) to obtain a semiquantitative measure of protein concentration, PDZD7 was present at $\sim 30$ molecules per stereocilium, with a $95 \%$ confidence interval of 2-300 molecules per stereocilium. This concentration was similar to that of GPR98 ( $\sim 20$ molecules per stereocilium; Fig. 1C,D) but greater than that of usherin (1 molecule per stereocilium; data not shown).

\section{Localization of PDZD7 at the stereocilia base}

Affinity-purified rabbit polyclonal antibody PB960 and the commercially available mouse polyclonal antibody YF-PA20973 were highly specific to PDZD7 and showed no cross-reactivity with either whirlin or harmonin in COS7 cells (data not shown). To investigate whether PDZD7 is part of the harmonin-sans complex at the UTLD, part of the ankle-link complex, or both, we examined its localization by whole-mount immunofluorescence on cochlea and vestibular sensory epithelia at several developmental stages. Although robust PDZD7 immunofluorescence reactivity was seen at stereocilia ankle-link region (Fig. $1 \mathrm{E}-$ $K, M, N)$, we could not detect it at the UTLD, where MYO7A clusters (Fig. $1 L$, arrowhead). This immunolocalization was corroborated by targeting of mCherry-tagged PDZD7, which predominantly localized to ankle-link regions of transfected organotypic organ of Corti and vestibular hair cells (Fig. 1OQ). Using a commercial rabbit polyclonal antibody to taperin, which is restricted to the tapered base of the stereocilia (Rehman et al., 2010), we localized PDZD7 just above and adjacent to the tapered stereocilia base, coinciding with the presumed ankle-link region (Fig. $2 A-C$ ).

\section{PDZD7 colocalization with stereocilia ankle-link proteins}

Whirlin has been localized to the ankle-link area of stereocilia in developing organ of Corti and vestibular hair cells and disappears
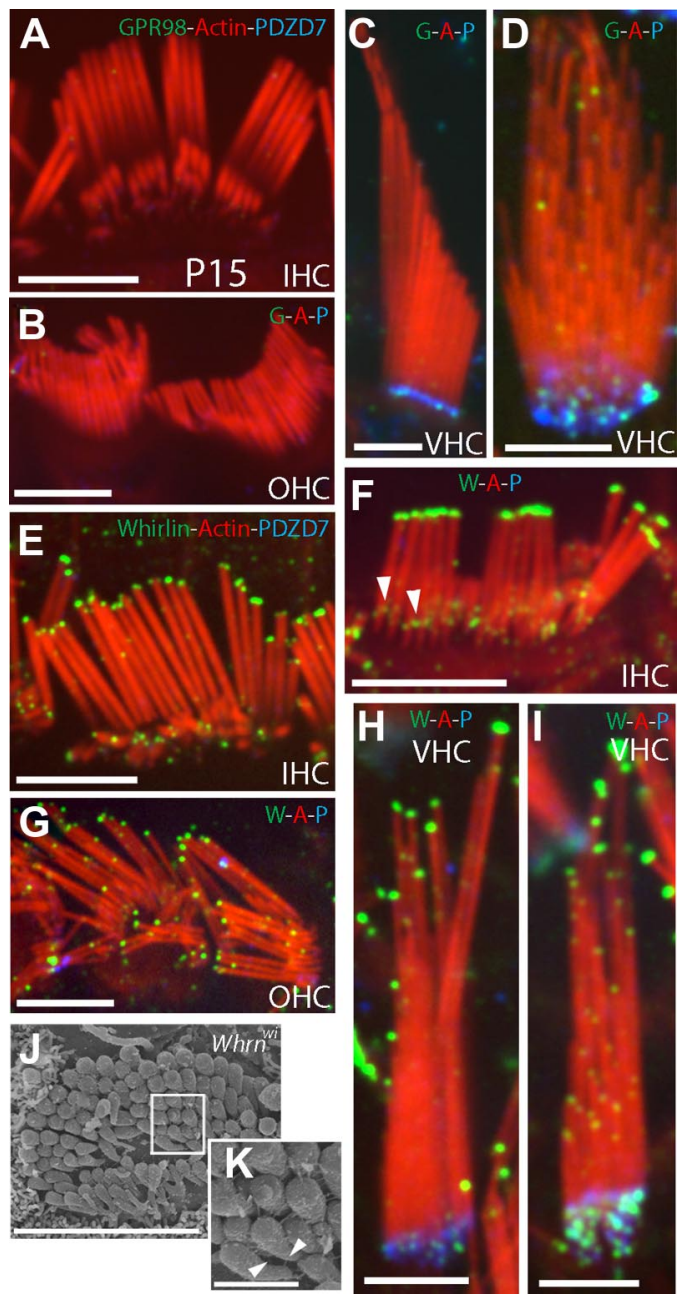

Figure 3. PDZD7 colocalization with stereocilia ankle-link proteins in mature rat hair cells $A-D$, PDZD7 (P) and GPR98 (G) colocalization in P15 hair cells. Both GPR98 (green) and PDZD7 (blue) are absent from mature inner $\mathrm{HCs}(\mathrm{IHCS} ; \boldsymbol{A})$ and outer $\mathrm{HCS}(\mathrm{OHC} ; \boldsymbol{B})$, following the disappearance of ankle-links. Red, actin (A). In mature VHCs where ankle-links persist, GPR98 (green) and PDZD7 (blue) fluorescence strongly overlap, as seen through longitudinal and oblique views of the stereocilia. $E-I$, PDZD7 (P) and whirlin (W) colocalization in P15 hair cells. In organ of Corti, PDZD7 (blue) is absent from mature inner $(\boldsymbol{E}, \boldsymbol{F})$ and outer $(\boldsymbol{G})$ HCs following the disappearance of ankle-links. Whirlin fluorescence (green) persists in stereocilia tips and some accumulation is visible around the ankle-link region $(\boldsymbol{F}$, arrowhead). Longitudinal $(\boldsymbol{H})$ and oblique (I) views of mature VHCs shows that PDZD7 fluorescence (blue) covers the regions where whirlin fluorescence (green) is present around the ankle-link area. In mature VHCS, whirlin is also seen concentrated at the stereocilia tips $(\boldsymbol{H}, \boldsymbol{I}) . \boldsymbol{J}$, Scanning electron micrograph of P10 whirler inner $\mathrm{HC}$ stereocilia showing short stereocilia that are interconnected with all sorts of links, including the ankle-links ( $\boldsymbol{K}$, arrowheads). Scale bars: $\boldsymbol{A}-\boldsymbol{J}, 5 \mu \mathrm{m} ; \boldsymbol{K}, 1 \mu \mathrm{m}$.

concomitantly from stereocilia of mature cochlear hair cells with the disappearance of the ankle-links (Michalski et al., 2007). Whirlin is presumed to scaffold the ankle-link proteins usherin and GPR98 since it interacts in vitro with their cytoplasmic tails (Adato et al., 2005; van Wijk et al., 2006). Whirlin is also present at stereocilia tips at all developmental stages, where it is a component of the myosin XVa-Eps8 complex, which regulates stereocilia length (Manor et al., 2011). Using immunocytochemistry-characterized antibodies specific to whirlin (see Materials and Methods, above; and data not shown), we studied its coimmunolocalization with PDZD7. Both proteins were found together at the ankle-link area of developing hair cells (Fig. 2D-H), but with limited fluorescence overlap, as indicated by the low Mander's and Pearson's coefficients $(r=0.64$, $\mathrm{Rr}=0.60$; Fig. $2 F$ ). 
GPR98 associates heterotypically with usherin to form extracellular ankle-links (Michalski et al., 2007). Since PDZD7 has been reported to interact in vitro with cytosolic tails of GPR98 and usherin (Ebermann et al., 2010), we investigated the colocalization of PDZD7 with GPR98 (Fig. 2I-K). Using a GPR98 antibody directed against its intracellular sequence, we found that GPR98 fluorescence strongly overlaps with that of PDZD7 along the ankle-link region (Mander's and Pearson's coefficients: $r=0.73, \mathrm{Rr}=$ 0.81 ; Fig. $2 I-K)$. In parallel, we investigated the colocalization of whirlin and GPR98 in maturing hair cells (Fig. $2 L-N$ ) and observed overlap between these two molecules along the ankle-link region (Fig. $2 L$, inset). In adult hair cells, anklelink fluorescence corresponding to PDZD7 or GPR98 was not seen in mature outer or inner hair cells (HCs; Fig. $3 A, B$ ), but persisted in mature vestibular $\mathrm{HCs}$ (VHC; Fig. 3C,D). However, whirlin localized to the tips of stereocilia of all mature hair cell types (Fig. 3E-I) and to the ankle-link region of mature VHCs (Fig. $3 H, I)$. Moreover, a visible residual accumulation of whirlin was observed in organ of Corti mature HCs (Fig. $3 F$ ).

\section{PDZD7 interactions with Usher proteins in COS7 and LLC-PK1 cells} In COS7 and LLC-PK1 cells, PDZD7 was predominantly cytosolic, but also colocalized with actin filament networks, particularly at cellular edges (Fig. 4A,B). PDZD7 colocalization with actin filaments likely depends on binding of PDZD7's central proline-serine-threonine rich domain to actin, as do harmonin-b isoforms (Boëda et al., 2002). We also reexamined the interactions of PDZD7 with sans and harmonin (Schneider et al., 2009) in COS7 cells (Fig. $4 A, B)$. A fraction of PDZD7 colocalized with sans (Fig. $4 A$ ) independently of actin filaments, consistent with data from pulldown assays (Schneider et al., 2009). However, PDZD7 was not associated with the actin plaques generated by harmonin crosslinking (Fig. 4B), suggesting that reported coimmunoprecipitation of harmonin and PDZD7 (Schneider et al., 2009) likely depends on their common actin binding. We also investigated the interactions of PDZD7 and whirlin with usherin and GPR98 cytosolic COOH-terminal tails in polarized LLC-PK1 cells (Fig. 4). For this purpose, we fused these tails to the $\mathrm{COOH}$ terminus of the IL2 receptor $\alpha$-subunit (IL2 $\alpha$ ), which targets to the plasma membrane; trafficking and targeting properties of these constructs can be influenced by exogenous cytosolic C-terminal sequences (Grati et al., 2006). Both IL2 $\alpha$-ush2a (Fig. $4 C, E$ ) and IL2 $\alpha$-GPR98 (Fig. $4 D, F)$ fusion proteins were highly enriched at the apical plasma membrane of LLC-PK1 cells, and each recruited PDZD7 (Fig. 4C,D) or whirlin (Fig. 4E,F), demonstrating that the cytosolic
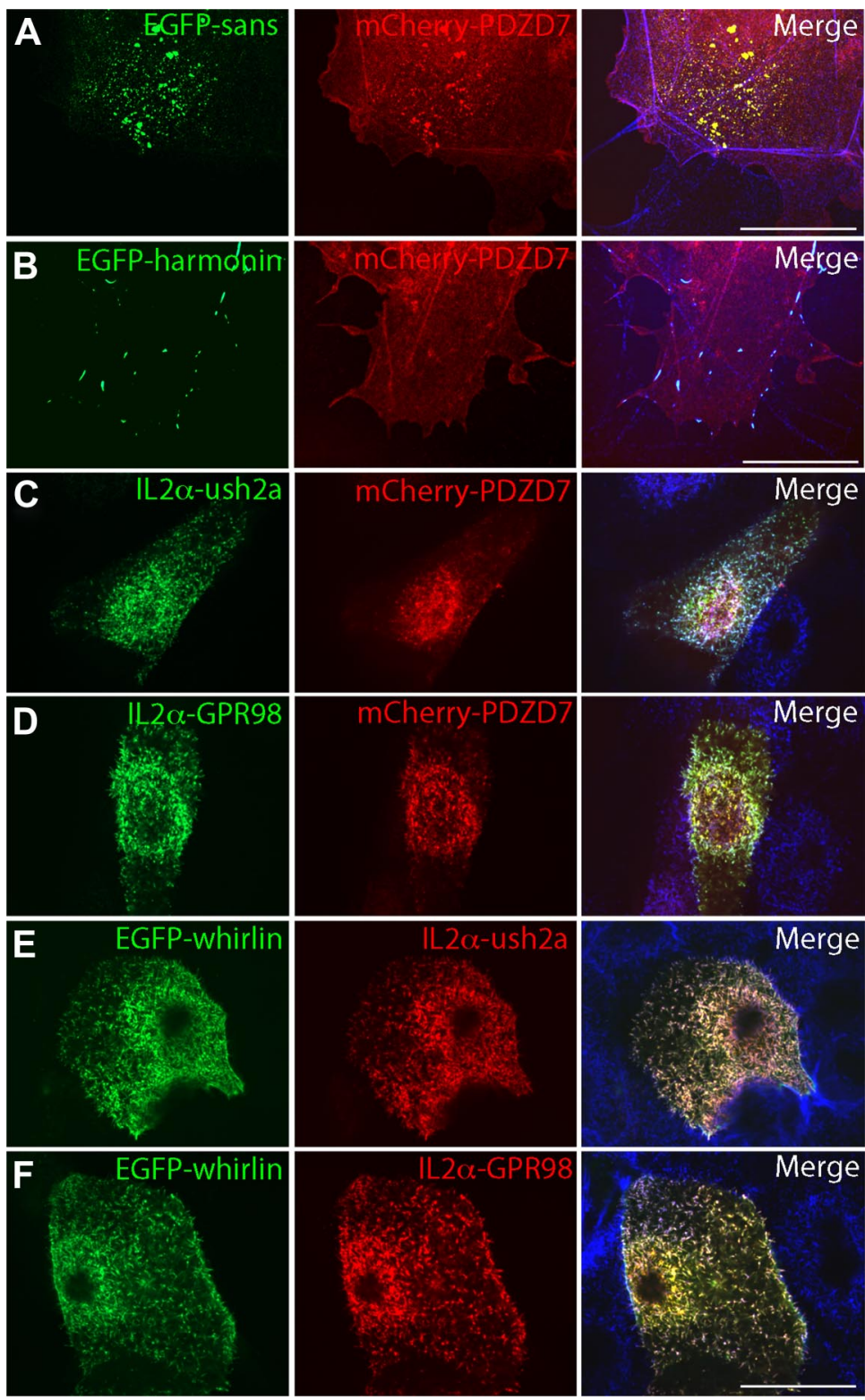

Figure 4. $A-\boldsymbol{F}$, PDZD7 interactions with Usher proteins in COS7 and LLC-PK1 cells. $\boldsymbol{A}$, In the presence of EGFP-sans (green), mCherry-PDZD7 (red) is randomly spread in the COS7 cell cytosol, associated with actin filaments (blue), or also recruited to EGFP-sans clusters, as shown by the high values of Mander's $(r=0.80)$ and Pearson's ( $R r=0.81)$ coefficients. $B$, EGFPcoexpressing fusion proteins IL2 $\alpha$-ush2a (green in $($ and red in $\boldsymbol{E}$ ) and IL2 $\alpha$-GPR98 (green in $\boldsymbol{D}$ and red in $\boldsymbol{F}$ ) together with eithe mCherry-PDZD7 (red in $\boldsymbol{C}, \boldsymbol{D}$ ) or EGFP-Whirlin (green in $\boldsymbol{E}, \boldsymbol{F}$ ), showing that both fusion proteins are enriched in the apical plasma membrane where they highly colocalize with both whirlin and PDZD7. Scale bars, $10 \mu \mathrm{m}$.

COOH-terminal tails of usherin and GPR98 can interact with both PDZD7 and whirlin.

\section{Discussion}

We show that PDZD7, a protein homologous to whirlin and harmonin, is exclusively located in the stereocilia ankle-link insertion sites at the site of the ankle-link complex and not found at the UTLD. This localization apparently conflicts with the reported in vitro interactions of PDZD7 with UTLD scaffolds harmonin and sans and our observation that sans is able to recruit PDZD7 in transfected COS7 cells. PDZD7 and sans in vitro interactions nevertheless suggests that these two molecules might as- 
sociate in the hair cell cytosol to traffic to the apical pole. Moreover, PDZD7 localization to the ankle-link region, together with its binding in vitro (Ebermann et al., 2010) and in LLC-PK1 cells to the cytoplasmic tails of usherin and GPR98, is consistent with its role as a USH2 phenotype modifier and structurally explains the cooperative effects of mutations in usherin and PDZD7, as well as that of GPR98 and PDZD7, causing a digenic USH2 phenotype (Ebermann et al., 2010). Accordingly, PDZD7 localization in the ankle-link makes it a good candidate to cause USH2 - but not USH1 - in humans, and suggests its inclusion in molecular diagnosis testing of USH2 patients.

In cross-sectional confocal views of hair bundle preparations, only a small fraction of PDZD7 fluorescence colocalized with that of whirlin at the ankle-link region. This implies that these two multi-PDZ domain-containing scaffolds could be playing a complementary role in the structure of the ankle-links and possibly in the molecular polarity of these structures. In the whirler mouse (B6.Cg-Whrn ${ }^{w i} \operatorname{Tyrp}^{b} /++\mathrm{J}$ ), carrying a deleterious mutation in $U s h 2 d$, the gene that encodes whirlin, stereocilia are unusually short but GPR98 immunofluorescence has been abundantly detected in maturing inner hair cells (Michalski et al., 2007). In these mutant hair cells, with well organized, cohesive, and staircase-shaped short stereocilia hair bundles, GPR98 likely forms interstereocilia links that can be seen by scanning electron microscopy (Fig. $3 \mathrm{~J}, \mathrm{~K}$ ). This result suggests that whirlin is not essential for scaffolding GPR98. However, usherin immunofluorescence was not detectable in innner $\mathrm{HC}$ bundles of the whirler mouse (Michalski et al., 2007), suggesting that whirlin is essential for scaffolding usherin at the ankle-link region. We propose that PDZD7 positions and stabilizes GPR98 at the ankle-link region of vestibular and maturing organ of Corti hair cells.

\section{References}

Adato A, Lefèvre G, Delprat B, Michel V, Michalski N, Chardenoux S, Weil D, El-Amraoui A, Petit C (2005) Usherin, the defective protein in Usher syndrome type IIA, is likely to be a component of interstereocilia ankle links in the inner ear sensory cells. Hum Mol Genet 14:3921-3932. CrossRef Medline

Boëda B, El-Amraoui A, Bahloul A, Goodyear R, Daviet L, Blanchard S, Perfettini I, Fath KR, Shorte S, Reiners J, Houdusse A, Legrain P, Wolfrum U, Richardson G, Petit C (2002) Myosin VIIa, harmonin and cadherin 23, three Usher I gene products that cooperate to shape the sensory hair cell bundle. EMBO J 21:6689-6699. CrossRef Medline

Bonnet C, Grati M, Marlin S, Levilliers J, Hardelin JP, Parodi M, NiasmeGrare M, Zelenika D, Délépine M, Feldmann D, Jonard L, El-Amraoui A, Weil D, Delobel B, Vincent C, Dollfus H, Eliot MM, David A, Calais C, Vigneron J, et al. (2011) Complete exon sequencing of all known Usher syndrome genes greatly improves molecular diagnosis. Orphanet J Rare Dis 6:21. CrossRef Medline

Craig R, Beavis RC (2004) TANDEM: matching proteins with tandem mass spectra. Bioinformatics 20:1466-1467.

Ebermann I, Phillips JB, Liebau MC, Koenekoop RK, Schermer B, Lopez I, Schäfer E, Roux AF, Dafinger C, Bernd A, Zrenner E, Claustres M, Blanco B, Nürnberg G, Nürnberg P, Ruland R, Westerfield M, Benzing T, Bolz HJ (2010) PDZD7 is a modifier of retinal disease and a contributor to digenic Usher syndrome. J Clin Invest 120:1812-1823. CrossRef Medline

Grati M, Kachar B (2011) Myosin VIIa and sans localization at stereocilia upper tip-link density implicates these Usher syndrome proteins in mechanotransduction. Proc Natl Acad Sci U S A 108:11476-11481. CrossRef Medline

Grati M, Aggarwal N, Strehler EE, Wenthold RJ (2006) Molecular determinants for differential membrane trafficking of PMCA1 and PMCA2 in mammalian hair cells. J Cell Sci 119:2995-3007. CrossRef Medline
Grillet N, Xiong W, Reynolds A, Kazmierczak P, Sato T, Lillo C, Dumont RA, Hintermann E, Sczaniecka A, Schwander M, Williams D, Kachar B, Gillespie PG, Müller U (2009) Harmonin mutations cause mechanotransduction defects in cochlear hair cells. Neuron 62:375-387.

Kazmierczak P, Sakaguchi H, Tokita J, Wilson-Kubalek EM, Milligan RA, Müller U, Kachar B (2007) Cadherin 23 and protocadherin 15 interact to form tip-link filaments in sensory hair cells. Nature 449:87-91. CrossRef Medline

Kros CJ, Marcotti W, van Netten SM, Self TJ, Libby RT, Brown SD, Richardson GP, Steel KP (2002) Reduced climbing and increased slipping adaptation in cochlear hair cells of mice with Myo7a mutations. Nat Neurosci 5:41-47. CrossRef Medline

Manor U, Disanza A, Grati M, Andrade L, Lin H, Di Fiore PP, Scita G, Kachar B (2011) Regulation of stereocilia length by myosin XVa and whirlin depends on the actin-regulatory protein Eps8. Curr Biol 21:167-172. CrossRef Medline

McGee J, Goodyear RJ, McMillan DR, Stauffer EA, Holt JR, Locke KG, Birch DG, Legan PK, White PC, Walsh EJ, Richardson GP (2006) The very large G-protein-coupled receptor VLGR1: a component of the ankle link complex required for the normal development of auditory hair bundles. J Neurosci 26:6543-6553. CrossRef Medline

Michalski N, Michel V, Bahloul A, Lefèvre G, Barral J, Yagi H, Chardenoux S, Weil D, Martin P, Hardelin JP, Sato M, Petit C (2007) Molecular characterization of the ankle-link complex in cochlear hair cells and its role in the hair bundle functioning. J Neurosci 27:6478-6488. CrossRef Medline

Pan L, Zhang M (2012) Structures of usher syndrome 1 proteins and their complexes. Physiology (Bethesda) 27:25-42. CrossRef Medline

Rehman AU, Morell RJ, Belyantseva IA, Khan SY, Boger ET, Shahzad M, Ahmed ZM, Riazuddin S, Khan SN, Riazuddin S, Friedman TB (2010) Targeted capture and next-generation sequencing identifies C9orf75, encoding taperin, as the mutated gene in nonsyndromic deafness DFNB79. Am J Hum Genet 86:378-388. CrossRef Medline

Rzadzinska AK, Schneider ME, Davies C, Riordan GP, Kachar B (2004) An actin molecular treadmill and myosins maintain stereocilia functional architecture and self-renewal. J Cell Biol 164:887-897. CrossRef Medline

Schneider E, Märker T, Daser A, Frey-Mahn G, Beyer V, Farcas R, SchneiderRätzke B, Kohlschmidt N, Grossmann B, Bauss K, Napiontek U, Keilmann A, Bartsch O, Zechner U, Wolfrum U, Haaf T (2009) Homozygous disruption of PDZD7 by reciprocal translocation in a consanguineous family: a new member of the Usher syndrome protein interactome causing congenital hearing impairment. Hum Mol Genet 18:655-666. Medline

Schneider ME, Dosé AC, Salles FT, Chang W, Erickson FL, Burnside B, Kachar B (2006) A new compartment at stereocilia tips defined by spatial and temporal patterns of myosin IIIa expression. J Neurosci 26:10243-10252. CrossRef Medline

Schwander M, Kachar B, Müller U (2010) Review series: the cell biology of hearing. J Cell Biol 190:9-20. CrossRef Medline

Shin JB, Longo-Guess CM, Gagnon LH, Saylor KW, Dumont RA, Spinelli KJ, Pagana JM, Wilmarth PA, David LL, Gillespie PG, Johnson KR (2010) The $\mathrm{R} 109 \mathrm{H}$ variant of fascin-2, a developmentally regulated actin crosslinker in hair-cell stereocilia, underlies early-onset hearing loss of DBA/2J mice. J Neurosci 30:9683-9694. CrossRef Medline

Spinelli KJ, Klimek JE, Wilmarth PA, Shin JB, Choi D, David LL, Gillespie PG (2012) Distinct energy metabolism of auditory and vestibular sensory epithelia revealed by quantitative mass spectrometry using MS2 intensity. Proc Natl Acad Sci U S A 109:E268-E277. CrossRef Medline

van Wijk E, van der Zwaag B, Peters T, Zimmermann U, Te Brinke H, Kersten FF, Märker T, Aller E, Hoefsloot LH, Cremers CW, Cremers FP, Wolfrum U, Knipper M, Roepman R, Kremer H (2006) The DFNB31 gene product whirlin connects to the Usher protein network in the cochlea and retina by direct association with USH2A and VLGR1. Hum Mol Genet 15:751-765. CrossRef Medline

Yang J, Wang L, Song H, Sokolov M (2012) Current understanding of usher syndrome type II. Front Biosci 17:1165-1183. CrossRef Medline

Zinchuk V, Zinchuk O (2008) Quantitative colocalization analysis of confocal fluorescence microscopy images. Curr Protoc Cell Biol Chapter 4:Unit 4.19. CrossRef Medline 